\title{
A Comparative Evaluation of Noninstrumentation Endodontic Techniques with Conventional ZOE Pulpectomy in Deciduous Molars: An in vivo Study
}

\author{
${ }^{1}$ Manisha Agarwal, ${ }^{2}$ Usha Mohan Das, ${ }^{3}$ Deepak Vishwanath \\ ${ }^{1}$ Senior Lecturer, Department of Pedodontics and Preventive Dentistry, AECS Maaruti College of Dental Sciences \\ and Research Center, Bengaluru, Karnataka, India \\ ${ }^{2}$ Former Professor and Head, Department of Pedodontics and Preventive Dentistry, VS Dental College \\ Bengaluru, Karnataka, India \\ ${ }^{3}$ Former Professor, Department of Pedodontics and Preventive Dentistry, Rajiv Gandhi College of Dental Sciences \\ Bengaluru, Karnataka, India
}

Correspondence: Manisha Agarwal, Senior Lecturer, Department of Pedodontics and P reventive Dentistry, AECS Maaruti College of Dental Sciences and Research Center, Bengaluru, Karnataka, India, e-mail: drmani29@ gmail.com

\section{ABSTRACT}

Pulp exposures secondary to caries are the most common in primary teeth due to the relatively large size of pulp chamber. Pulp in primary teeth is capable of healing, following control of infection and inflammation. Pulpotec and LSTR are the simple noninstrumentation endodontic treatment procedures which are capable of compensating for the inconvenience caused by conventional pulpectomy, and thereby preserve the vitality of the pulp. This study was conducted to assess clinical efficacy of pulpotec and LSTR and compare with that of conventional ZOE pulpectomy at $1,3,6$ and 12 months postoperatively. Around 34 children in the age group of 4 to 9 years with deep carious lesions affecting the pulps of 60 primary mandibular molars were randomly divided into three groups with 20 teeth in each group.

Results: Clinical evaluation was done at 1 month's interval. Both clinical and radiographic evaluations were done at 3, 6 and 12 months. Data obtained was analyzed statistically using Fisher's exact test. The results concluded that pulpotomy and pulpotec could be a good alternative for conventional ZOE pulpectomy. Long-term radiographic evaluations should be undertaken to further strengthen the efficacy of lesion sterilization and tissue repair (LSTR) as NIET.

Keywords: Vital pulp treatment, ZOE pulpectomy, Pulpotec, LSTR.

\section{INTRODUCTION}

One of the most val uable services a pediatric dentist can provide for the child patient is adequate treatment of pulp involved primary teeth. ${ }^{1}$ For many years, different principles and techniques for the treatment and preservation of primary teeth have been suggested by the dental profession. ${ }^{2}$

Pulp therapy has been suggested since 1932 as a method for maintaining primary teeth, which would otherwise be lost. ${ }^{3}$ Pul pectomy procedure is al ways just a compromise but which taking proper indication into account, is preferred to an extraction. Still, pulpectomy procedure proves to be long and complicated and has remained controversial for a number of reasons. M ainly, the perceived difficulty of behavior management in the pediatric population and uncertainty about the effects of root canal filling material and instrumentation on the succedaneous teeth. A natomic situations like the often complicated curved and tortuous shape of root canals and the closeness of the advancing tooth buds make the treatment more difficult. ${ }^{4} A$ nother limitation is the apparent connection between the coronal floor with the intraradicular area ${ }^{5}$ with the presence of multiple accessory canals and ramifications as well as the difficulty in obtaining hermetic seal due to lack of apical cl osure following physiologic root resorption have surely added reluctance among dentists to use this procedure. ${ }^{6}$ Hence, the use of such procedure should be discouraged. ${ }^{7}$ The literature on pulpal treatment for primary teeth predicate on the premise that the pulp remains vital or that a portion of it will retain vitality after therapy. ${ }^{8}$ The pulp and pulpal reactions in primary teeth differ markedly as it inflames more easily, degenerates more readily and reacts less favorably than that of permanent teeth. The high degree of cellularity and vascularity is an asset to high potential of repair. As such the young pulp lends itself most readily to procedures concerned with preservation of pulp vitality. ${ }^{9}$

This has led to investigate the possibilities of perfecting a material with simplified procedure, capable of compensating for the inconveniences, and thereby preserving the vitality and promote pulp tissue healing. ${ }^{10}$ To overcome the difficulties, preparations containing antibiotics and corticosteroids have been proposed as the alternatives with the possibility of active suppression of acute inflammation thereby preserving the vitality of pulp that has been regarded as irreversibly inflamed. ${ }^{11}$

Use of the newer materials and techniques in the recent years, such as that of Pulpotec proposed by A M armesse ${ }^{10}$ for the treatment of pul pitis of deciduous molars by pulpotomy ${ }^{10-12}$ and 
another al ternative, the concept of lesion sterilization and tissue repair (LSTR) therapy proposed by Hoshino ${ }^{13}$ and I waku et $\mathrm{al}^{14}$ can prove to be beneficial alternatives to conventional ZOE pulpectomy. They employ the use of minute amounts of corticosteroids and mixture of antibacterial drugs respectively, to sterilize the root canal system but not mechanical procedure. These clinical procedures are simpleand do not require multiple visits and have been designated as noninstrumentation endodontic treatment techniques (NIET). ${ }^{15}$

B oth the techniques present numerous advantages when compared to conventional pulpectomy. One can mention significant time saving, easy access to the coronal part of the pulp which is treated with simplified procedure. ${ }^{12}$

However, there are few reports in the literature regarding the use and clinical efficacy of these procedures. There are also no previous studies concerning which of these simplified techniques give the higher percentage of success. M oreover, data is also insufficient regarding the clinical efficacy of these noninstrumentation techniques when compared with conventional procedures in primary teeth.

So, this study was conducted to determine the clinical efficacy of Pulpotomy, Pulpotec and LSTR therapy as noninstrumentation endodontic procedures and simultaneously compare their clinical and radiographic results with those of conventional ZOE pulpectomy as control on primary mandibular molars.

\section{METHODOLOGY}

A short-term clinical study was conducted on 60 primary mandibular molars, showing signs of pulpal involvement in 4 to 9 years old children free from systemic disease, who reported to the Department of Pedodontics and Preventive Dentistry, V S Dental College and Hospital, B engaluru, India.

\section{CRITERIA FOR TOOTH SELECTION USING CLINICAL AND RADIOGRAPHIC EXAMINATION}

1. Primary molars with vital carious pulp exposure that show evidence of hyperemia with or without partial necrosis or abscess formation

2. No clinical symptom or evidence of radicular pulp degeneration

3. Radiographic features:

- No radiographic signs of internal/external root resorption

- No furcation radiolucency

4. No pathologic mobility

5. No sinus or fistula formation

6. Teeth should be restorable.

The selected teeth were divided randomly into:

Group 1 (Fig. 1)

Control

Twenty primary mandibular molars were treated with conventional ZOE pulpectomy procedure according to Payne et al, 2004. ${ }^{16}$

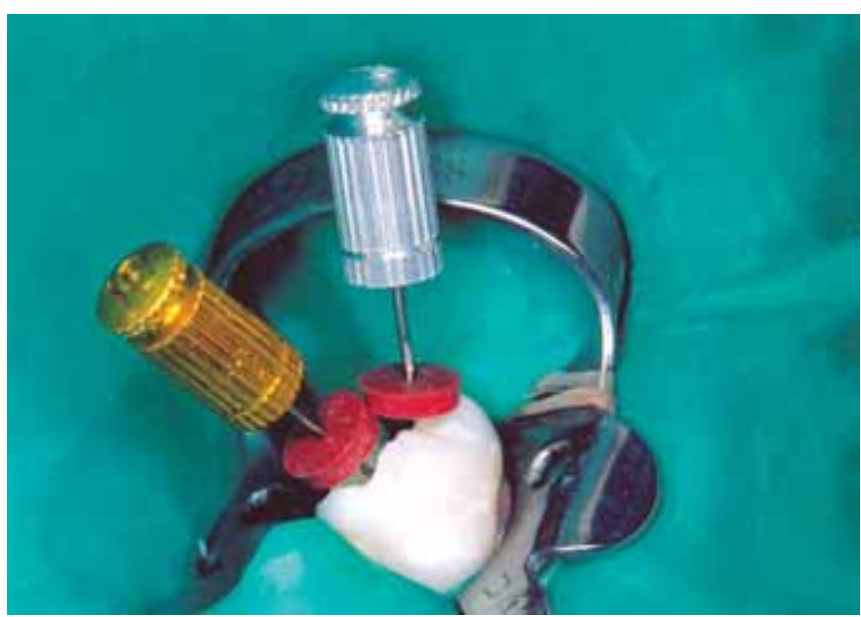

Fig. 1: Conventional ZOE pulpectomy

Local anesthesia was given followed by Rubber dam application. A ccess cavity was prepared using no. 56 fissure bur in N SK high speed ai rotor handpiece. Complete amputation of coronal pulp using spoon excavator was done to gain entrance into the root canal identified at the floor of pulp chamber. Pulp tissue extirpation was done using no. 15, $20 \mathrm{H}$ files, one at a time. Working length established $1 \mathrm{~mm}$ short of apex by inserting fine files by taking IOPAR. Following which biomechanical preparation was done using $\mathrm{H}$ files, rotating them to engage the pulp tissue and removed in a pull back motion with frequent irrigation with normal saline. The canals dried using sterile absorbent paper points for obturation with a paste of ZOE mixed to medium consistency, delivered using lentulospirals and the material was finally condensed using root canal pluggers. Postoperative IOPAR was taken after completion of procedure. The tooth was then restored after 24 hours with stainless steel crown.

\section{Group 2 (Fig. 2)}

\section{Experimental}

Twenty primary mandibular molars were treated with pulpotomy and pulpotec (Pulpotec kit contains pow der and liquid, carbide

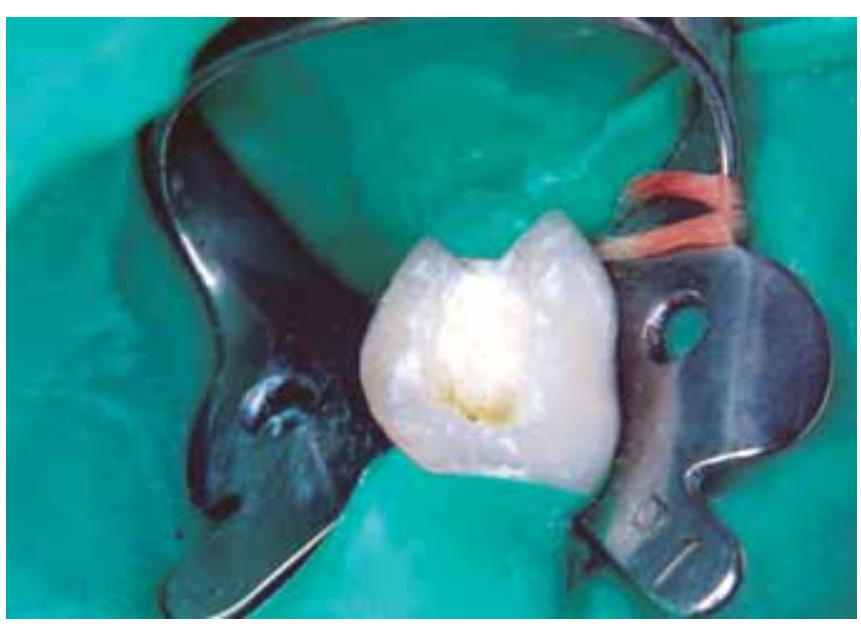

Fig. 2: Pulpotomy and Pulpotec 
surgical bur, endo bur, diamond pear shaped bur and pastefiller) procedure. $^{10}$

A fter preoperative assessment, local anesthesia was given along with rubber dam placement. Roof of pulp chamber was removed using surgical bur after which vital pulp was excised from the chamber by means of endo bur. Shape the pul p chamber using diamond pear shaped bur. Pulpotec liquid and powder were blended to obtain thick, creamy consistency of the paste which was inserted into the pulp chamber using paste filler. The cavity was then sealed with temporary ZOE cement. The patient was then asked to bite progressively but firmly on the cotton placed between the two dental arches, so that the paste clings to the walls of the pulp cavity as well as to the root canal orifices. Excess cement was eliminated and postoperative IOPAR taken after completion of procedure. Once the initial set has occurred (after 7 hours), second session was undertaken to complete the treatment by seating stainless steel crown.

\section{Group 3 (Fig. 3)}

\section{Experimental}

Twenty primary mandibular molars were treated with 'Iesion sterilization and tissue repair therapy' (LSTR-3M ix-M P, mixture of drug combination of ciprofloxacin 500, metronidazole 400 and minocycline 100 in a ratio of 1:3:3 prepared with macrogol and propylene glycogol in ointment form) procedure. ${ }^{15}$

Once the preoperative assessment was made, local anesthesia administration and rubber dam application were done. A ccess cavity was then prepared using no. 56 fissure bur in high speed NSK airotor handpiece. $5 \% \mathrm{NaOCI}$ immersed in cotton was applied to control the hemorrhage, followed by application of the antibiotic paste to the pulpal floor. The tooth was then sealed with GIC and postoperative IOPAR was taken after completion of procedure. Permanent restoration was done by cementing stainless steel crown in second appointment after 24 hours.

The children were recalled for clinical evaluation at the interval of 1 month; clinical and radiographic 3, 6 and 12 months.

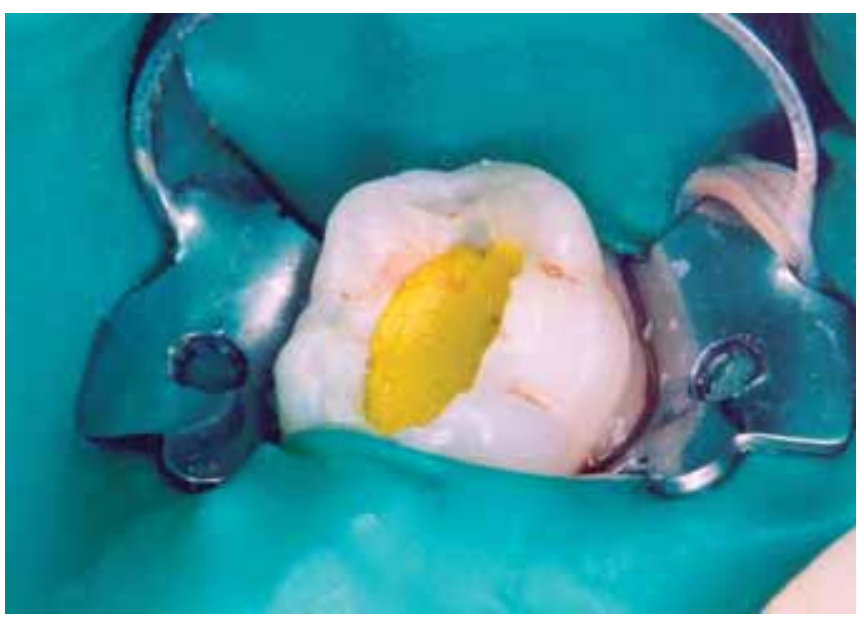

Fig. 3: LSTR (3 Mix-MP placed over the pulp stump)

\section{Scoring Criteria $^{17}$}

Scoring for clinical success of teeth:

0 . Failure

1. No pain symptoms

2. No tenderness to percussion

3. No swelling

4. No fistula

5. No pathologic mobility.

Scoring for radiographic success of teeth:

0 . Failure

1. No radicular radiolucency

2. No internal/external root resorption

3. No periodontal ligament space widening.

[Failure (0): Defined as presence of any one or more of the above clinical and/or radiographic signs and symptoms].

\section{RESULTS}

A total of 60 mandibular primary molars, 26 first molars and 34 second molars in 34 children (18 males, 16 females) were endodontically treated in group I (ZOE) and in group 2 (Pulpotec) and 3 (lesion sterilization and tissue repair) where noninstrumentation directed endodontic treatment was carried out. The symptoms of the patients were recorded regarding the status of the pulp and single sitting roof canal procedure was carried out (Table 1).

Statistical Analysis was done using Fisher's exact test to compare the proportion of failure/success (Tables 2 to 5 ) in the three groups at different time intervals (Graphs 1 to 4). Null hypothesis $\mathrm{H} O$ taken was that there is no significant difference in the proportion of failures among the three groups, i.e. p1 = p2 = p3 and the alternate hypothesis $\mathrm{H} 1$ was that at least one pair of the groups differ with level of significance being

Table 1: Distribution of teeth according to presenting symptoms

\begin{tabular}{lcccc} 
Group & $\begin{array}{l}\text { Teeth with } \\
\text { deep carious } \\
\text { lesions and } \\
\text { exposed pulp }\end{array}$ & Acute symptoms & Abscess & Asymptomatic \\
& 20 & 13 & - & 7 \\
\hline 1 & 20 & 12 & 1 & 7 \\
2 & 20 & 13 & - & 7 \\
3 & & &
\end{tabular}

Table 2: Cumulative distribution of failure and success in each group at 1 month

\begin{tabular}{lclc} 
Group & Failures & Success & $p$-value (Fisher's test) \\
\hline $1(n=16)$ & 0 & $16(100 \%)$ & 1.000 \\
$2(n=20)$ & 0 & $20(100 \%)$ & \\
$1(n=16)$ & 0 & $16(100 \%)$ & 0.024 \\
$3(n=20)$ & $6(30 \%)$ & $14(70 \%)$ & \\
$2(n=20)$ & 0 & $20(100 \%)$ & 0.020 \\
$3(n=20)$ & $6(30 \%)$ & $14(70 \%)$ &
\end{tabular}


Table 3: Cumulative distribution of failure and success in each group at 3 months

\begin{tabular}{lccc} 
Group & Failures & Success & $\begin{array}{l}\text { p-value } \\
\text { (Fisher's test) }\end{array}$ \\
\hline $1(n=16)$ & 0 & $16(100 \%)$ & 1.000 \\
$2(n=20)$ & $1(15 \%)$ & $19(95 \%)$ & \\
$1(n=16)$ & 0 & $16(100 \%)$ & $<0.001$ \\
$3(n=18)$ & $10(55.56 \%)$ & $8(44.44 \%)$ & \\
$2(n=20)$ & 0 & $20(100 \%)$ & 0.001 \\
$3(n=18)$ & $10(55.56 \%)$ & $8(44.44 \%)$ &
\end{tabular}

Table 4: Cumulative distribution of failure and success in each group at 6 months

\begin{tabular}{lcrc} 
Group & Failures & Success & $\begin{array}{c}\text { p-value } \\
\text { (Fisher's test) }\end{array}$ \\
\hline $1(n=14)$ & $1(7.14 \%)$ & $13(92.86 \%)$ & 1.000 \\
$2(n=19)$ & $1(5.26 \%)$ & $18(94.74 \%)$ & \\
$1(n=14)$ & $1(7.14 \%)$ & $13(92.86 \%)$ & 0.003 \\
$3(n=18)$ & $11(61.11 \%)$ & $7(38.89 \%)$ & \\
$2(n=19)$ & $1(5.26 \%)$ & $18(97.74 \%)$ & $<0.001$ \\
$3(n=18)$ & $11(61.11 \%)$ & $7(38.89 \%)$ & \\
& & &
\end{tabular}

Table 5: Cumulative distribution of failure and success in each group at 12 months

\begin{tabular}{lrrc} 
Group & \multicolumn{1}{c}{ Failures } & \multicolumn{1}{c}{ Success } & $\begin{array}{l}\text { p-value } \\
\text { (Fisher's test) }\end{array}$ \\
$1(n=14)$ & $3(21.43 \%)$ & $11(78.57 \%)$ & 0.288 \\
$2(n=19)$ & $1(5.26 \%)$ & $18(94.73 \%)$ & \\
$1(n=14)$ & $3(21.43 \%)$ & $11(78.57 \%)$ & 0.016 \\
$3(n=18)$ & $12(66.67 \%)$ & $6(33.33 \%)$ & \\
$2(n=19)$ & $1(5.26 \%)$ & $18(94.73 \%)$ & $<0.001$ \\
$3(n=18)$ & $12(66.67 \%)$ & $6(33.33 \%)$ &
\end{tabular}

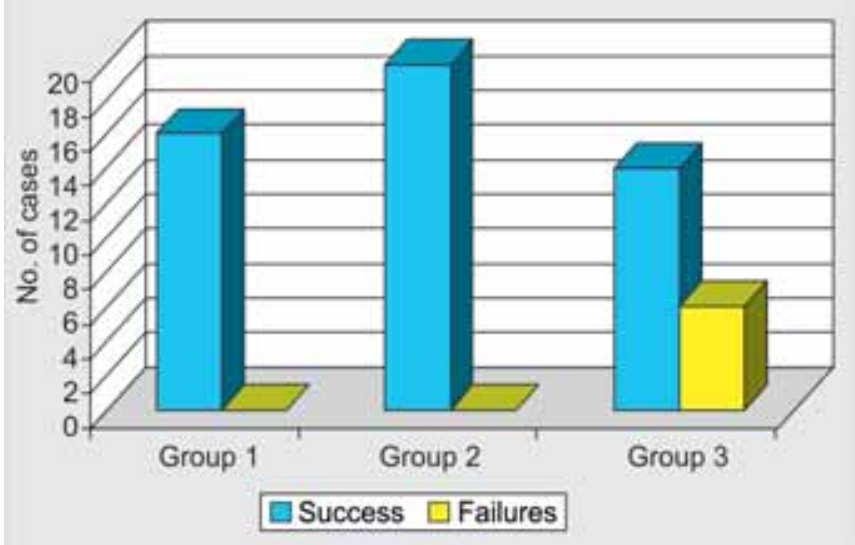

Graph 1: Graphic representation of success and failure in each group at 1 month

$\alpha=0.05$. The decision criterion was to reject the null hypothesis if $p<0.05$ and accept the alternate hypothesis. Otherwise we accept $\mathrm{H} O$.

Inference The following Tables 2 to 5 give us the significance value, i.e. the $p$-value for various computations. W e notice that $p<0.05$ between group 1, group 3 and group 2, group 3 at all time intervals. Thus, we reject $\mathrm{HO}$ and conclude that there is a significant difference in the proportion of failures/success

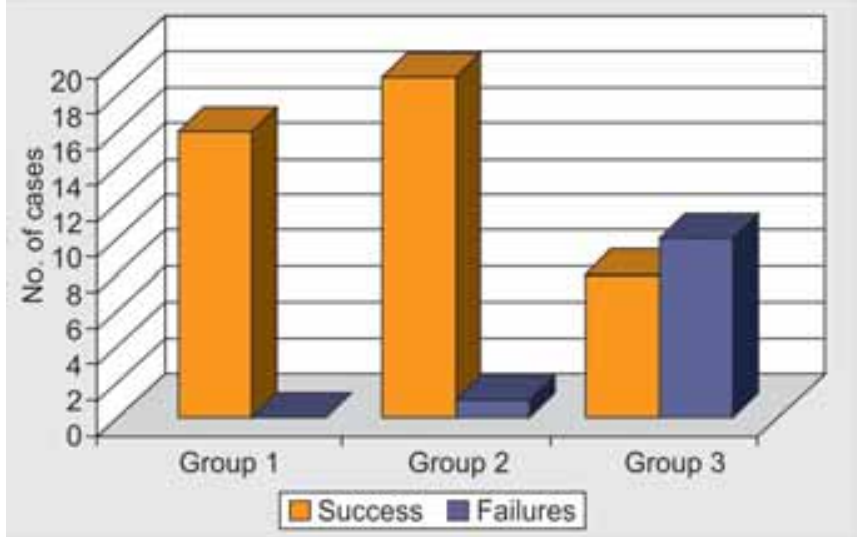

Graph 2: Graphic representation of success and failure in each group at 3 months

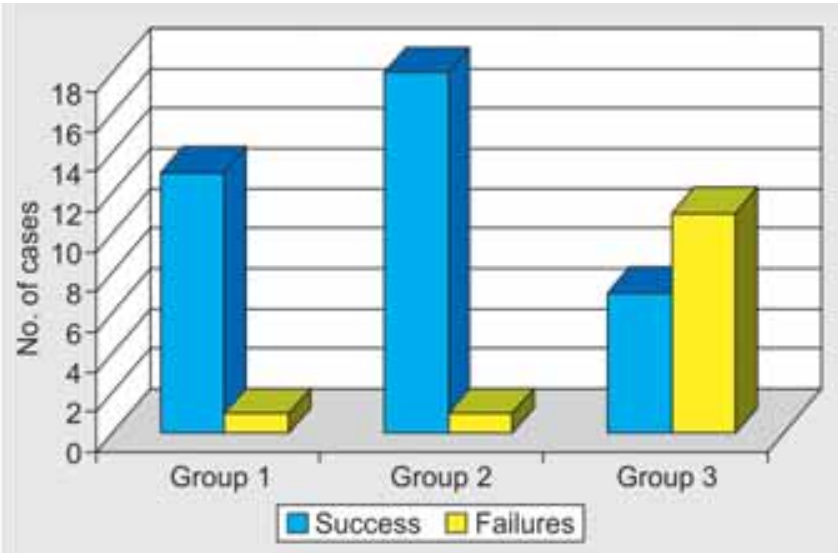

Graph 3: Graphic representation of success and failure in each group at 6 months

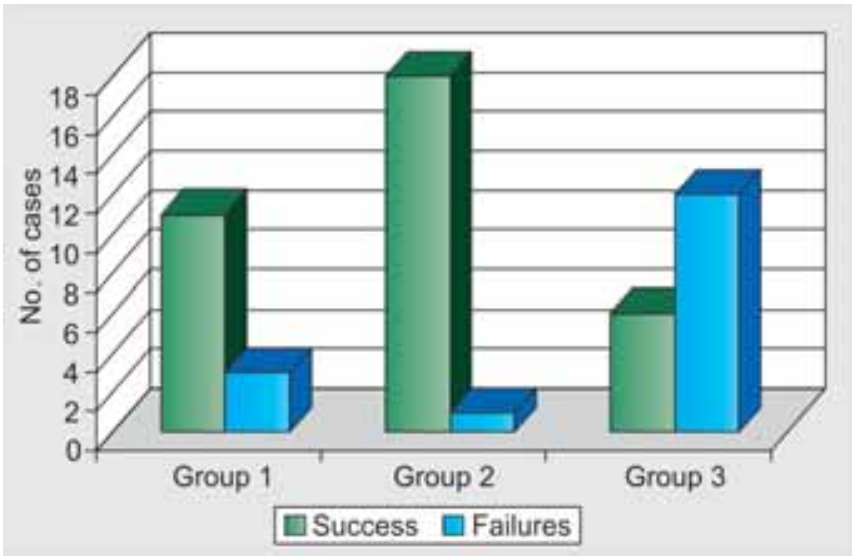

Graph 4: Graphic representation of success and failure in each group at 12 months

between group 1, group 3 and group 2, group 3. B ut for group 1 and group 2, p > 0.05, at all time intervals. Therefore, we accept the null hypothesis $\mathrm{HO}$ and conclude that there is no significant difference in the proportion of failures/success between group 1 and group 2 .

\section{DISCUSSION}

One of the most val uable services a pediatric dentist can provide for the child patient is adequate treatment of pulp involved 
primary teeth. ${ }^{1} \mathrm{M}$ aintaining the integrity and health of oral tissues is the primary objective of pulp treatment.Conservative treatments are recommended for primary teeth whose pulps have the potential to recover once the irritation is removed.

$V$ arious techniques have been described for conserving primary molars whose pulps have become nonvital or have degenerated to the extent that they are not good candidates for vital pulp therapy. M ost of these techniques can be assigned to one of two major classifications. Representatives of one group advocate removing the contents of pulp chamber and placing some sort of medication over the radicular pulp stump for a varying period of time. Representatives of the second group advocate removing all accessible pulp tissue, controlling the organisms and their toxins with a rotation of drugs, and restoring the canals with an absorbable filling material. ${ }^{18}$

M CD onalds $R$ advocates partial pulpectomy technique for deciduous teeth that have hyperemic pulp without painful pulpitis. ${ }^{19}$ The usual treatment applied to pulpitis on a vital tooth is pulpectomy. ${ }^{12} \mathrm{ZOE}$ is the most widely used preparation for primary tooth pulpectomies. ${ }^{20}$ E rausqin and $M$ uruzabal used ZOE as a root canal filling material in 141 rats follow ed from 1 to 90 days. They noted that ZOE irritated the periapical tissues and caused necrosis of bone and cementum. ${ }^{21}$

In 1982, Jerrell and Ronk presented a case report of overfilled ZOE pulpectomy in which succedaneous premolar was malformed. ${ }^{22}$ Coll et al in 1985 reported a more than $80 \%$ success rate of one-visit ZOE pulpectomy followed a mean time of 70 months. They found $Z O E$ retained in the tissue after eight of 17 molars exfoliated. ${ }^{23}$

A natomic situations like the of ten-complicated shape of root canals and the closeness of the advancing tooth bud make root canal treatment difficult. ${ }^{5}$ Groter $(1967)^{24}$ advocated to avoid the use of instruments completely while Spedding $(1973)^{25}$ advocated to use instruments in the root canals to the point of resistance. Y acobi et al $(1991)^{26}$ were in favor of minimal biomechanical preparation. Garcia Godoy (1987) ${ }^{27}$ preferred to enlarge the root canals only to the level of occlusal plane of the permanent tooth germ.

Hobson $1970^{28}$ found that tubules in the dentinal walls of the root canals, in $70 \%$ of the samples of extracted teeth with necrotic in both radicular and coronal pulp, were penetrated by microorganisms. He concluded that it would be desirable, therefore, when treating nonvital infected primary teeth to use an antibacterial drug capable of penetrating the tissues and controlling infection in the dentinal walls.

Several investigators agree that total removal of the pulp tissue from the root canals of primary teeth cannot be achieved because of their complex and variable morphology. It is also difficult to eliminate the wide range of organisms in infected root canals. Thus, the particular quality of the medicament/paste determines the prognosis in the endodontic treatment of infected primary teeth. Identifying the best formulation of ingredients and techniques to predictably produce pulpal healing remains elusive. It is generally agreed that prognosis after any type of the pulp therapy improves in the absence of contamination by pathogenic organisms. Thus, biocompatible neutralization of any existing pulpal contamination and prevention are worthy goals in vital pulp therapy. If the treatment material in direct contact with pulp al so has some inherent quality that promotes, stimulates or accelerates a true tissue healing response, so much better, however, it is recognized that vital pulp tissue can recover from a variety of insults spontaneously in a favorable environment. 29

N oninstrumentation endodontic treatment procedures applied to the use of Pulpotec and lesion sterilization and tissue repair are based on the above concepts.

The overall success rate of ZOE (78.5\%) was consistent with the results of M ortazavi $M$ and M esbahi $M(2004)^{39}$ who also reported the overall success rate (clinical and radiographic) of $78.5 \%$ for ZOE at the end of 10 to 16 months follow-up period. The results were al so in comparison with the study done by $M$ ani, Chawla and Tewari et al $(2000)^{34}$ who reported $83.3 \%$ clinical and radiographic success rate in the ZOE group followed up to 6 months.

The overall success of $94 \%$ in "Pulpotec" at the end of 12 months was al so in agreement with the results of $M$ aramesse $A$ (1989) ${ }^{13}$ who conducted clinical trials of Pul potec for long-term and found a success rate of $80 \%$ in deciduous teeth. Our results were also consistent with those of Dodeyan SA, Donkaya IP $(2003)^{36}$ who reported $100 \%$ success rate of Pulpotec during 6 months evaluation.

In this in vivo study, the overall (clinical and radiographic) success rates in LSTR at the end of 12 months were not on agreement with those of $\mathrm{H}$ oshino $\mathrm{E}(2004)^{16}$ who reported $80 \%$ clinical success of the procedure. Overall three patients were seen with intraoral swelling at the end of 6 months follow-up and the main complications encountered were radicular radiolucency and internal resorption on radiographic followup at 6 and 12 months intervals. The poor success rate can be attributed to the fact that radiographic criteria were al so used to assess the success, which was not done in the earlier studies. There are limited and conflicting reports in the literature to substantiate the clinical and radiographic success rate of LSTR.

From the above study, it was concluded that "Pulpotec" can be used as a proven, safe and effective alternative to conventional ZOE pulpectomy in teeth with pulpal exposure secondary to caries with or without partial necrosis, which eliminates the need to instrument into the canals and simplifies the procedure.

We recommend further long-term clinical and radiographic evaluations for LSTR before it can be recommended as NIET.

\section{CONCLUSIONS}

1. Our study concluded that pulpotomy and pulpotec could be a good al ternative for conventional ZOE pulpectomy

2. Long-term clinical and radiographic eval uations should be undertaken to further strengthen the efficacy of LSTR as NIET. 


\section{REFERENCES}

1. Rifkin A. A simple, effective, safe technique for the root canal treatment of abscessed primary teeth. J Dent Child Nov-Dec 1980;435-41.

2. Boller RJ. Reactions of pulpotomized teeth to zinc oxide and formocresol type drugs. J Dent Child July-A ug 1972:52-61.

3. Kubota K, Golden BE, Penugonda B. R oot canal filling materials for primary teeth: A review of the literature. J Dent Child M ayJ une 1992;225-27.

4. Holan G, Fucks A B. A comparison of pulpectomies using ZOE and KRI paste in primary molars: A retrospective study. Pediatric Dentistry 1993;15:403-07.

5. M Oss SJ , A ddelston R, Goldsmith ED. H istologic study of pulpal floors of deciduous molars. JADA 1965;70:372.

6. Mathewson RJ, Primoch RE, M orrison JT. Fundamentals of pediatric dentistry ( $3 \mathrm{rd}$ ed). Quintessence Publishing Co Inc 1995:257-84.

7. Massler N. Preventive endodontics. DCNA N ov 1967;670.

8. Gould J M. R oot canal therapy for infected primary molar teeth: Preliminary repot. J Dent Child July-A ug 1972;23-27.

9. Stewart RE, Barber TK, Trouman KC, Wei SHY. Pediatric dentistry scientific foundations and clinical practice. The CV M osby Company.

10. http://www.pulpotec.com.

11. Schroeder U, Graneth L. On internal dentine resorption of deciduous molars treated by pulpotomy and capped with calcium hydroxide. Odontol Review 1971;22:179.

12. M armesse A. Final reports of clinical trials of pulpotec (Translation of the original text). U npublished article (http:// www.pulpotec.com)

13. Hoshino E. Sterilization of carious lesions by drugs. J of the J apanese Association for D ental science 1990;9:32-37.

14. Iwaku M, Hoshino E, K ota K. Lesion sterilization and tissue repair therapy: N ew pulpal treatment, how to conserve infected pulps. Tokyo, J apan: Nihon-Shika-H oron 1996.

15. Takushige T, Cruz EV, M oral AA, Hoshino E. Endodontic treatment of primary teeth using a combination of antibacterial drugs. International endodontic Journal 2004;37:132-38.
16. Payne RG, K enny D J, J ohnston D H, J udd PL. T wo-year outcome study of zinc oxide-eugenol root canal treatment for vital primary teeth. J Can Dent A ssoc 1993;59:528-36.

17. A gamy HA, Bakry N S, M ounir M M F, A very DR. Comparison of mineral trioxide aggregate and formocresol as pulp capping agents in pulpotomized primary teeth. Ped Dent 2004;26: 302-09.

18. Starkey PE. Pulpectomy and root canal filling in primary molars: Report of a case. J Dent Child M ay-J une 1973;49-53.

19. Donald RE, A very DR, Dean JA. Dentistry for the child and adolescent. St L ouis: CV M osby Company 1978:146-68.

20. Sardian R, Coll JA. A long-term follow-up on the retention rate of zinc oxide eugenol filler after primary tooth pulpectomy. Pediatric Dentistry 1993;15:249-53.

21. E rausquin J, M uruzabal M. R oot canal fillings with zinc oxideeugenol cement in the rat molar. Oral Surg O ral M ed O ral Pathol 1967;24:547-58.

22. J errell RG, Ronk SL. Developmental arrest of a succedaneous tooth following pulpectomy in a primary tooth. J Pedod 1983;6:337-42

23. Coll JA, J osell S, Casper J S. Evaluation of a one-appointment formocresol pulpectomy technique for primary molars. Ped Dent 1985;7:123-29.

24. Groter JA. Pulp therapy in primary teeth. J Dent Child 1967;34:508-10.

25. Spedding RH. Root canal treatment for primary teeth. DCNA 1973;17:105-24.

26. Y acobi R, K enny DJ, J udd PL, J ohnston DH. Evolving primary pulp therapy techniques. JADA 1991;122:83-85.

27. Garcia Godoy C. Evaluation of iodoform paste in root canal therapy for infected primary teeth. J D ent C hild 1987;54:30-34.

28. Hobson P. Pulp treatment of deciduous teeth. BDJ 1970;128: 232-8, 275-82

29. M ortazavi $M$, Mesbahi $M$. Comparison of zinc oxide and eugenol, and $V$ itapex for root canal treatment of necrotic primary teeth. Int J of Ped Dent 2004;14:417-24. 